\title{
AS PRÁTICAS RESTAURATIVAS COMO ACESSO À JUSTIÇA E SOLUÇÕES DE CONFLITOS NO ÂMBITO DA LEI 11.340/2006.
}

\section{RESTAURANT PRACTICES AS ACCESS TO JUSTICE AND CONFLICT SOLUTIONS UNDER LAW 11.340/2006}

\author{
Rosane Teresinha Porto* \\ Marli Marlene Moraes Da Costa* \\ Geliana Dáfini Da Silva**
}

\section{RESUMO}

O presente trabalho intitulado "As práticas restaurativas como acesso à justiça e soluções de conflitos no âmbito da Lei 11.340/2006" tenciona analisar a viabilidade da implementação da política pública em conflitos domésticos a partir da Lei Maria da Penha e das Resoluções 125 e 225 do CNJ. Na mesma linha, pretendeu-se observar evolução da respectiva legislação, os desafios enfrentados pelas vítimas em momentos de isolamento social, bem como, características e princípios da Justiça Restaurativa, com enfoque na aplicação. Desta forma, questiona-se: há possibilidade de aplicação da Justiça Restaurativa como política pública em casos de violência doméstica visando o acesso à justiça e a pacificação de conflitos? Para o desenvolvimento da presente pesquisa será utilizada a abordagem dedutiva e quanto ao método de procedimento, este será o bibliográfico.

Palavras-chave: Ciclo da Violência. Justiça Restaurativa. Lei Maria da Penha. Resolução 125 do CNJ.

\footnotetext{
*Doutora em Direito pela Universidade de Santa Cruz do SUI - UNISC/RS. Mestre em Direito na área de concentração: Políticas Públicas de Inclusão Social com bolsa da Coordenação de Aperfeiçoamento de Pessoal de Nível Superior - CAPES . Estágio Pós-Doutoral em Direito pela Universidade La Salle, sob a orientação do Dr. Daniel Achutti. Pós-Doutoranda pela Universidade Federal do Rio Grande Sul (UFRGS) sob orientação da Dra. Luciane Cardoso Barzotto. Especialização pela PUC/RS em Docência no Ensino Superior. Especialização pela PUC/RS em Nova Educação, Metodologias e foco no aluno. Professora Permanente na Universidade Regional do Noroeste do Estado do Rio Grande do Sul - UNIJUÍ, lecionando na graduação em Direito e no Programa de Pós Graduação em Direito - Mestrado e Doutorado. Professora na graduação em direito e na Pós Lato Sensu na UNISC . Estuda temáticas voltadas a criança e adolescente, direitos sociais, Acesso à Justiça e soluções de conflitos entre elas: mediação e justiça restaurativa. Integrante do Grupo de Pesquisa Biopolítica \& Direitos Humanos (CNPq). Integrante do grupo de pesquisa Direito e Fraternidade da UFRGS (Capes/CNPQ). Integrante da equipe de trabalho do projeto Rede de cooperação Academia e de pesquisa: eficiência, efetividade e economicidade nas políticas de segurança pública com utilização de monitoração eletrônica e integração de banco de dados (EditalProcad/Capes n.16/2020). Pesquisadora RecémDoutora ARD- FAPERGS: Fundo de Amparo à Pesquisa do Estado do Rio Grande do Sul (Edital FAPERGS 10/2020). Coordenadora da Rede de mediação sanitária na América Latina (2021). Endereço eletrônico: rosane.cp@unijui.edu.br

* Doutora em Direito pela Universidade Federal de Santa Catarina - UFSC, com pós-doutoramento em Direito pela Universidade de Burgos - Espanha, com bolsa CAPES. Professora da Graduação e da Pós-Graduação Lato Sensu em Direito da Universidade de Santa Cruz do Sul - UNISC. Professora do Programa de Pós-Graduação em Direito - Mestrado e Doutorado da UNISC. Coordenadora do Grupo de Estudos Direito, Cidadania e Políticas Públicas do PPGD da UNISC. MBA em Gestão da Aprendizagem e Modelos Híbridos de Educação. Especialista em Direito Privado. Psicóloga com Especialização em Terapia Familiar. Membro do Conselho Consultivo da Rede de Pesquisa em Direitos Humanos e Políticas Públicas. Membro do Núcleo de Pesquisas Migrações Internacionais e Pesquisa na Região Sul do Brasil - MIPESUL. Integrante do Grupo de Trabalho em Apoio a Refugiados e Imigrantes (GTARI/UNISC). Membro do Conselho Editorial de inúmeras revistas qualificadas no Brasil e no exterior. Autora de livros e artigos em revistas especializadas. ORCID: http://orcid.org/0000-0003-3841-2206 E-mail: marlim@unisc.br

*** Graduada em Direito pela Universidade de Santa Cruz do Sul. Integrante do Grupo de Pesquisas Direito, Cidadania \& Políticas Públicas, vinculado ao Programa de Pós-Graduação em Direito - Mestrado e Doutorado, da UNISC, coordenado pela Pós-Dr. ${ }^{a}$ Marli Marlene Moraes da Costa. Pesquisadora na área de Direito, com ênfase em Direito da Mulher. Endereço eletrônico: gedafini@hotmail.com
} 


\section{ABSTRACT}

The present work entitled "Restorative practices as access to justice and conflict solutions under Law 11.340 / 2006" intends to analyze the feasibility of implementing public policy in domestic conflicts based on the Maria da Penha Law and Resolutions 125 and 225 of CNJ. In the same vein, the intention was to observe the evolution of the respective legislation, the challenges faced by the victims in moments of social isolation, as well as the characteristics and principles of Restorative Justice, with a focus on enforcement. Thus, the question arises: is it possible to apply Restorative Justice as a public policy in cases of domestic violence aimed at access to justice and the pacification of conflicts? For the development of this research the deductive approach will be used and as for the method of procedure, this will be the bibliographic.

Keywords: Restorative Justice. Maria da Penha Law. CNJ Resolution 125. CNJ Resolution 225.

\section{INTRODUÇÃO}

Com a introdução da Lei 11.340/2006 juntamente com o sistema retributivo, a concepção de que o processo judicial põe fim ao litígio se torna uma falácia, ao passo que a sentença somente determina "quem perdeu e quem ganhou" e ao olharmos para o conflito, nada mudou. O sentimento de insatisfação e a dilação do Judiciário gera um desgaste psicológico, associado com a da desesperança.

A Justiça Restaurativa sobrevém como uma política diferenciada, na busca pela escuta dos envolvidos, colocando-os no mesmo patamar. A ideia do perde e ganha é substituída pelo diálogo e pela pretensão de uma solução conjunta, prevenindo assim, novos atos de violência.

A partir da exposição, a pesquisa visa esclarecer o seguinte questionamento: há possibilidade de aplicação da Justiça Restaurativa como política pública em casos de violência doméstica visando o acesso à justiça e a pacificação de conflitos? Com isso, propõem-se a examinar a viabilidade da implementação da Justiça Restaurativa em casos de violência doméstica a partir da Lei 11.340/2006 e das Resoluções 125 e 225 do CNJ, seus princípios e características, utilizando-se, de uma retomada acerca da origem histórica da Lei 11.340/2006, trazendo um enfoque quanto a cultura patriarcal e ao ciclo da violência.

Desse modo então, o artigo é dividido em três capítulos, no qual, no primeiro analisa-se a origem histórica da Lei 11.340/2006, bem como seus desafios, já no segundo, parte-se da verificação da efetividade da Lei Maria da Penha e o enfrentamento do ciclo da violência no atual momento, qual seja, a Covi-19 e, por fim, no terceiro capítulo, será explanado acerca da retribuição e da restauração, expondo os princípios e práticas adotadas.

\section{A LEI 11.340/2006: SUA ORIGEM E DESAFIOS FRENTE A UMA CULTURA PATRIARCAL}

Este capítulo tem por objetivo analisar a evolução dos direitos das mulheres no Brasil, bem como, explanar as legislações que conduzem. Ainda, visa percorrer o que diz respeito às desigualdades existente entre os gêneros e a violência praticada contra as mulheres.

$\mathrm{O}$ art. $5^{\circ}$ da Lei conceitua a Violência Doméstica como qualquer ação ou omissão baseada no gênero que lhe cause morte, lesão, sofrimento físico, sexual ou psicológico e dano moral ou patrimonial.

No mesmo sentido é necessário relatar a origem da mulher que deu nome à Lei. Maria da Penha, farmacêutica, casada com Marco, este economista e professor universitário. Teve três filhas e foi vítima de inúmeras agressões e inclusive duas tentativas de homicídio. Na primeira, houve simulação 
de assalto com uso de uma arma de fogo, onde ficou paraplégica. Com seu retorno do hospital, Marco tentou eletrocutá-la. (DIAS, 2019)

Com receio, se calou. Tinha conhecimento do álibi do seu marido: "matou por amor". O que tornava tudo mais difícil. Num momento de coragem, procedeu com a denúncia, resultado: não obteve providência alguma. Tamayo (2002) corrobora, no sentido em que as mulheres são obrigadas a se encobrirem diante de violências, ao passo que esquecidas de uma proteção estatal, tornam-se uma quimera calada.

Perante todos acontecimentos, Maria da Penha redigiu um livro, o que desencadeou uma denúncia a Comissão Interamericana de Direitos Humanos da Organização dos Estados Unidos, através do Centro pela Justiça e o Direito Internacional concomitantemente com o Comitê Latino-Americano e do Caribe para a Defesa dos Direitos da Mulher. Dessa forma, a denúncia foi considerada a pioneira proveniente de Violência doméstica.Com o tempo, o Brasil determinou o cumprimento das Convenções e Tratados Internacionais. (DIAS, 2019)

Diante de atos de violência contra as mulheres que representam discriminação, de acordo com a Convenção sobre a Eliminação de Todas as Formas de Discriminação contra a Mulher e constituem violações a direitos e liberdades fundamentais, protegidos por instrumento como o Pacto Internacional de Direitos Civis e Políticos, a Convenção Americana sobre Direitos Humanos e a Convenção Interamericana para Prevenir, Punir e Erradicar a Violência contra a Mulher, os Estados têm obrigações de realização imediata.

A Violência Doméstica, conforme o art. $7^{\circ}$ da Lei 11.340/2006, pode ocorrer de várias formas, dentre elas: física, psicológica, sexual, patrimonial e a moral. A violência física, por sua vez, independe de marcas aparentes, uma vez que o uso de agressão física, por si só, já caracteriza o vis corporalis, expressão que elucida tal violência. (DIAS, 2019)

Ademais, na violência psicológica, a utilização do método gaslighting, termo utilizado na década de 1960, começou a ser empregado para definir fenômenos psicológicos, onde através de mentiras e manipulações, possui como objetivo a alteração de percepção da vítima. (SARKIS, 2019)

$\mathrm{Na}$ mesma senda, temos o mansplaining que ocorre quando um homem esclarece episódios notórios à mulher, na maioria das vezes com um tom soberbo, transparecendo à esta, que seria incapaz de compreender algo. Assim, a vítima se torna mais vulnerável. Como o padrão abusivo é gradual, faz com que a vítima se torne cada vez mais dependente de seu parceiro, se distanciando de familiares e amigos. (DIAS, 2019)

Outrossim, a violência sexual decorre da ideologia do débito conjugal, nome criado no Direito Canônico, com a finalidade de regular relações sexuais existentes entre cônjuges, isto é, uma forma de legitimar um dos deveres matrimoniais, o de coabitação. (LOPES, 2005).

Em outras palavras, pode ser conceituado como o direito-dever que um cônjuge tem frente ao outro no que tange ao relacionamento sexual entre eles. Isto é, o marido tem o direito de exigir a "prestação" de tal dever, enquanto que a mulher tem a obrigação de "adimpli-lo", e vice-versa. Advinha, contudo, a possibilidade de anulação do casamento pela ausência de contato sexual, não reconhecendo a prática de estupro, caso o ato fosse praticado mediante violência, pois era conhecido como exercício regular do direito inerente ao casamento. (DIAS, 2019)

A violência patrimonial, por sua vez, objetiva causar dor e sofrimento a vítima, desconsiderando o valor do bem. Possui ligação direta com a violência psicológica. Já a violência moral, dizem respeito 
aos elencados na esfera da proteção a honra, contudo, há incidência da Lei 11.340/2006 considerando a natureza afetiva. (DIAS, 2019)

Outrossim, a violência contra a mulher assevera a manifestação das relações de poder, ressaltando a desigualdade entre homens e mulheres. Ainda, estabelece ofensa contra a dignidade humana que perdura toda a sociedade, não importando classe social, renda, grupo étnico, nível educacional, religião ou idade. Consequentemente a erradicação da violência contra a mulher é condição fundamental para seu desenvolvimento tanto individual, como social. (CAVALCANTI, 2018) Como marco primordial neste sentido é a declaração de Viena de 1993, sendo o primeiro instrumento internacional que singularizou a expressão direitos humanos da mulher. (PORTO, 2014)

Além disso, vivemos em um mundo que entre homens há muitas diferenças e entre mulheres também. Porém, o que não deve ocorrer é a desigualdade. A sociedade constrói as desigualdades a partir das diferenças, convertendo as diferenças em desigualdades. (MORAES; RUBENS, 2002)

Conforme Tamayo (2002, p. 34):

Historicamente, é no espaço doméstico, que tem sido cometida, sistematicamente, as práticas de violência de gênero. No entanto, tem sido o tipo de vínculo entre vítimas e agressores, mediado por construções de gênero, a condição determinante para que essas práticas tenham sido mantidas como questões do âmbito privado e fora da intervenção pública. Com o conceito de violência doméstica o que se faz é apenas adicionar um cenário e representar, grosso modo, diversas modalidades e resultados lesivos.

Igualmente, a denúncia da violência psicológica tem respaldo nas relações desiguais de gêneros, ocorrendo, muitas vezes, com mais frequência. Contudo, é a prática menos denunciada, pois a mulher muitas vezes não percebe que tais tensões, manipulações e agressões verbais consistem em violência também. (DIAS, 2007)

Nesse contexto, há tese do concurso heterogêneo, justificada por Brito (2018), Juíza Desembargadora no Tribunal de Relação de Évora, atentando errôneo desconsiderar a punição de um ofensor somente por um crime no âmbito da violência doméstica ou apenas o mais grave, quando por longo período de tempo, o que também poderia ser curto, este ofensor violou os direitos da vítima, agrediu, perseguiu, praticou tentativas de homicídio e muitas vezes, chegou as vias de fato, não seja condenado em concurso heterogêneo.

Tamayo (2002, p. 26) defende:

O direito das mulheres a uma vida livre de violência é um enunciado exigente e urgente. Não se refere a um tratamento de exceção que a firma a sua natural vulnerabilidade, em sua formulação tratou-se, apropriadamente, de revelar, e como consequência, corrigir a falta de proteção de exceção que jurídica e institucionalmente vêm tendo os direitos das mulheres. Em sua conceituação, ratificam-se direitos humanos de aplicação universal e se reconhecem como violações a estes um conjunto de atos lesivos que até então não tinham sido apreciados como tais. É um direito que repões o princípio da igualdade, fazendo com o que tudo seja violento, prejudicial e dano para as mulheres seja considerado como ofensivo para a sociedade.

O princípio constitucional que norteia a igualdade entre homens e mulheres está elencado no art. $5^{\circ}, \mathrm{I}$, dispondo os direitos e garantias fundamentais em relações interfamiliares e domésticas com consequências em legislações infraconstitucionais, tal como no direito penal e no direito de família. (TAMAYO, 2002) 
Outrossim, a principal conquista das mulheres no Brasil está consignada no artigo 226, parágrafo $8^{\circ}$, da Constituição, o qual dispõe: "O Estado assegurará a assistência à família na pessoa de cada um dos que a integram, criando mecanismos para coibir a violência no âmbito de suas relações".

Ademais, a sociedade não detém a ideologia que a violência vivenciada pela mulher surgiu de um culpa exclusiva do ofensor. Falas como "ele pode não saber por que bate, mas ela sabe por que apanha" é uma expressão distorcida e cultural, decorrente de desigualdades no exercício do poder, o que propiciou a formação de dois mundos: um de dominante, produtor e externo e outro de submissão, reprodutor e interno. As mulheres, como educação diferenciada sempre foram limitadas a seus desejos e pensamentos. A virgindade, o sacrifício da maternidade e o depósito no casamento ideal com o ápice da felicidade: ser a dona do lar, ter casa e filhos para cuidar e um marido para amar. (DIAS, 2019)

Além disso, o ambiente familiar sempre foi um ambiente restrito e privado de intervenção estatal e corroborando com outros aspectos, teve uma grande contribuição para o excessivo aumento da violência entre ambiente familiar. Também, o constrangimento para denunciar combinado com a falta de informação, cedeu espaço para o ofensor, que na maioria das vezes, era marido, companheiro ou namorado. (VALADARES, 2017)

Portanto, a violência surge neste contexto, ao passo que o ofensor justifica a agressão como forma de reparar possíveis "falhas" no desempenho de seu gênero. A honra do ofensor gera uma percepção "falsa" de legítima defesa como excludente de ilicitude. (GIDDENS, 1996)

Realizada abordagem histórica sobre a Lei Maria da Penha enquanto mecanismo para coibir a violência doméstica, bem como, os diversos fundamentos que resultaram a promulgação, de suma importância seguir a análise com enfoque na efetividade da respectiva legislação e no enfrentamento do ciclo da violência tendo em vista a Covid-19 e o isolamento social.

\section{UMA ANÁLISE DA EFETIVIDADE DA LEI MARIA DA PENHA NO BRASIL E O ENFRENTAMENTO DO CICLO DA VIOLÊNCIA DIANTE DA COVID-19.}

De grande importância a temática no presente trabalho, ao tecer sobre o assunto, mostraremos a efetividade, ou não da lei 11.340/2006, dados extraídos do Atlas da Violência quanto a violência de gênero e uma atualização de medidas adotadas para o enfrentamento da violência praticada em lares, cenário atual acometido por muitos em tempos de Covid-19.

As formas de punição de autores de condutas diversas das tidas como corretas sempre gerou uma problemática para a ciência jurídico-social. (KIST, 2019) Mulheres, sejam elas do campo, indígenas, negras, trabalhadoras rurais ou urbanas, vivenciam a exclusão de seus direitos sociais em sua plenitude, bem como, a exiguidade de políticas públicas, a dificuldade no acesso tanto aos serviços para o gênero, quanto as oportunidades para alcançar o poder. (GONZATTI; SILVA, 2019)

Ademais, a complexidade das demandas familiares e o acúmulo do Poder Judiciário geram uma demora na tramitação, o que ocasiona um alto custo para os envolvidos, impessoalidade na decisão alude um colapso instituído, assim como ao julgar o processo, onde magistrado somente põe fim na demanda, contudo, não há resolução do conflito. (MARCANTONIO, 2014)

Outrossim, mister ainda avanços legais e jurídicos na busca pelo enfrentamento e ampliação dos direitos das mulheres a partir de políticas públicas. Existe a manutenção dos índices de violência, 
levando a presumir que somente a criminalização dos atos violadores juntamente com a proteção das vítimas não está sendo o suficiente. (GONZATTI; SILVA, 2019)

Essy (2016) argumenta que as vítimas amedrontadas com ameaças, não prosseguem com a denúncia, ou ao realizá-la, prontamente já renunciam à representação, considerando o medo de uma nova violência ou até mesmo a angústia que o agressor possa chegar ao ápice das agressões, ou seja, que cometa um homicídio.

Além disso, Costa (2014, p. 75) aduz que

[...] apesar de a Lei Maria da Penha ser considerada um grande avanço como instrumento de proteção à violência do homem contra a mulher, ela ainda está longe de atingir o objeto almejado de combate e prevenção da violência de gênero, por meio de seu caráter punitivo [...]

Existem diversas justificativas que não permitem, de fato, que a Lei Maria da Penha assegure a proteção das mulheres no âmbito de suas residências. Na teoria, seria um sucesso, caso houvesse a assistência necessária. Contudo, a carência de uma rede estatal bem articulada, engajada em realmente dar todo o suporte necessário é omisso, fazendo com que a eficácia fique somente no papel, pois na prática, a realidade é outra, não havendo qualquer facilidade na busca de obter a mínima proteção que faz jus. (ESSY, 2016)

Neste viés, foi realizada pesquisa de opinião pelo DataSenado (BRASIL, 2017) onde analisaram respostas de 2.400 pessoas onde destas, $60 \%$ afirmaram que possuem conhecimento de mulheres vítimas de algum tipo de violência doméstica. Ainda, 89\% do segmento que afirmou ter ciência, declaram que a vítima pertence a seu âmbito pessoal, proporção que indica o quanto a violência é rotineira e que não está distante das pessoas. Quanto as formas, $82 \%$ afirmam que se tratou de violência física, 39\% psicológica, 33\% moral, 13\% sexual e 11\% moral. 01\% não soube responder.

Além disso, questionadas sobre a proteção da Lei Maria da Penha diante da violência doméstica e familiar, $21 \%$ das mulheres não se sentem protegidas, enquanto que $47 \%$ se sentem em parte, o que demonstra, cristalinamente, o medo sofrido pelo desamparo. Tal resultado, reflete diretamente nos índices de denúncia, onde $61 \%$ afirmaram que uma minoria das mulheres denunciaria e $24 \%$ se calaria. O fator: medo do ofensor, liderando com 68\%. (BRASIL, 2017)

A partir dos dados apresentados, nota-se que há uma padronização quanto ao ciclo da violência, que corresponde a três fases, sejam elas: acúmulo de tensão, explosão e lua-de-mel.

A fase de acúmulo de tensão, por sua vez, perdura normalmente bastante tempo e de forma gradual. O início, no geral, ocorre com agressões verbais, discussões, provocações, podendo progredir para episódios de agressões físicas leves. Para evitar tais ocorrências, nesta fase, a mulher assume uma atitude submissa, ao passo que a tensão vai aumentando até perder o controle e desencadear uma agressão grave, mediante ataques de fúria, o que identifica a fase de explosão. Além disso, é nesta fase que a vítima realiza a denúncia ou procura amparo em algum abrigo. Porém, a maioria das mulheres violentadas não buscam auxílio, a menos que necessitem de cuidados médicos diante da gravidade das lesões. (WALKER, 2009)

Após o ápice da violência, inicia-se a fase da lua-de mel, onde o ofensor, arrependido e com conduta gentil e amorosa, pretende reparar a vítima acerca da agressão sofrida. A vitimização da mulher ocorre nessa fase, à medida que ela modifica seu estado de ânimo para mais confiante e amoroso. Ao mesmo tempo, se sente pressionada a preservar o relacionamento perante a sociedade e também quando possui filhos com o ofensor na esperança que o mesmo irá mudar. O ciclo regressa e cada 
fase se torna mais agressiva, provocando, na maioria das vezes, um final amedrontador: o homicídio da mulher. (WALKER, 2009)

Corroborando com tal afirmação, através de dados do Atlas da Violência (IPEA, 2019), delimitando a década de 2007 a 2017 em relação aos homicídios de mulheres no Brasil, houve um crescimento muito significante, relativo a 30,7\%, assim como houve um aumento de 6,3\% em relação a 2016. Outrossim, casos de homicídios dentro de lares se expandiu, cerca de 17,1\%. Dessa forma, a violência na concepção de Gonzatti e Silva (2019) "é comum, sendo que pode variar entre diária, semanal ou mensal, transformando-se em hábito na vida da mulher, como qualquer outra tarefa, entre elas acordar, trabalhar e ser violentada".

Ademais, vivemos uma situação muito delicada em virtude do Covid-19, popularmente chamado de Coronavírus. A recomendação da Organização Mundial de Saúde (ONU) é o isolamento social.

Contudo, determinada medida tem auxiliado na contenção da disseminação do vírus e por consequência, a diminuição. Mas por outro lado, a precaução tem implicações negativas tanto na economia, como também na segurança pública. (CASTRO, 2020)

Ainda, considerando que informalidade é mais comum entre mulheres do que entre homens, bem como que muitas estão afastadas de seus trabalhos, ocasionando a dependência financeira do companheiro, gerando uma relação "imposta" e angustiante. Destarte, uma pessoa que talvez nunca bateu, pode ter desencadeado a agressão física. (BIANQUINI, 2020)

No Estado do Rio de Janeiro, por exemplo, a partir das medidas preventivas de isolamento social não foram somente os índices de Coronavírus que se avultaram, mais os da violência também, em indicadores correspondentes a 50\%. (MAZZI, 2020)

Outrossim, ainda que os números apontem um aumento expressivo, há subnotificação, tendo em vista diversos fatores, como: dificuldade de sair de casa em virtude da dependência financeira do marido ou companheiro, ocupação com os filhos, já que estes estão sem frequentar a escola, assim como o receio de contrair o vírus. Para Andrade (2020), não houve diminuição da violência, muito pelo contrário, a incidência está ainda maior, porém mais característico nas residências e de uma forma mais privada.

A Ponte Jornalismo, através da série "Um vírus e duas guerras", monitora os casos de feminicídios e de violência doméstica durante o período da pandemia com o intuito de demonstrar as agressões silenciosas e despercebidas por muitos, fortalecendo a rede de apoio e impulsionar a criação ou manutenção de políticas públicas de prevenção à violência de gênero no Brasil. Igualmente, apresentou recentemente um levantamento sobre violência doméstica entre os meses de março e abril deste ano, onde salientou que os feminicídios no País expandiram numa proporção correspondente a 05\% em relação a igual período de 2019. Apenas nos meses referidos, 195 mulheres foram assassinadas, ao passo que em 2019, na mesma delimitação, foram 186 mortes. (PONTE, 2020)

Assim, visando romper o ciclo da violência preservar a integridade das mulheres, Olga (2020) preconiza conservar serviços essenciais assistir as vítimas, bem como, criação de novas plataformas de serviços com ênfase no momento vivido objetivando o aumento na assistência a nível local e territorial. Além disso, aconselha a retirada de prováveis gatilhos, como instrumentos que trazem algum risco (pontiagudos), por exemplo, remoção de qualquer tipo de droga ou bebidas alcoólicas e manutenção da comunicação com familiares ou outra pessoa. 
Há medidas de enfrentamento em vários estados do Brasil. Especificamente no Rio Grande do Sul, a promotora Ivana Battaglin da Promotoria de Justiça Especializada de Combate à Violência Doméstica e Familiar contra a Mulher de Porto Alegre, afirmou que a assistência às mulheres continua e que as mesmas podem realizar denúncias pela Delegacia online. Em situações que demandam necessidade das medidas, as vítimas devem comparecer à delegacia para serem orientadas e informadas. (MENDES, 2020)

Visando o rompimento do ciclo da violência e na busca do diálogo entre os envolvidos, faz-se necessária uma abordagem a respeito do sistema retributivo e do Restaurativo, a fim de compreendermos as diferenças e, consequentemente, a aplicação das práticas.

\section{DA RETRIBUIÇÃO À RESTAURAÇÃO: UMA NOVA PERSPECTIVA NA PACIFICAÇÃO DE CONFLITOS, SEUS PRINCÍPIOS E PRÁTICAS ADOTADAS}

A Justiça Criminal tem como principal objetivo manter o convívio pacífico entre os membros da sociedade. Para tanto, o Estado detém o poder punitivo. (TORTEGA, 2016). Com o advento da Lei Maria da Penha no Brasil houve alteração no método de punição, originando Juizados de Violência Doméstica e Familiar que conforme os artigos 17 e 41 da respectiva Lei, os quais vedam a execução da Lei 9.099/95 e proíbem a conversão em penas pecuniárias, multa isolada e cesta básica. Ainda, determina a assistência às mulheres através da Defensoria Pública ou assistências Judiciárias Gratuitas, bem como, aplicação de medidas protetivas. Tal violação deixou de ser um crime de menor potencial ofensivo e passou a ser executável, com a prisão do ofensor. (VASCONCELOS; SOUZA, 2017)

Outrossim, o Estado possui a incumbência no domínio da sociedade, dispondo de normas de conduta com o fito de resguardar a serenidade, impedindo atitudes ilícitas. Não obstante, tais normativas, ao passo que impugnadas, resultam na sanção do culpado pela desobediência, objetivando recompor a ordem anteriormente estabelecida. Tal teoria é a conhecida como retributiva da pena. (BITTENCOURT, 2012 apud COSTA, 2014).

Neste viés, a ideologia de que uma contenção total irá remediar os danos causados às vítimas e totalmente descabida e ilusória, à medida que os direitos fundamentais são afrontados devido a uma incapacidade estatal em solucionar o gatilho que, de fato, implica na violência. (LOPES JÚNIOR, 2016)

Ademais, Kist (2019) afirma que existem situações consideráveis que consternam o procedimento utilizado atualmente, citando a falta de conhecimento quanto as fases do processo penal e dentre elas: ausência de esclarecimento quanto ao processo, bem como, as diversas etapas, os prazos, idas ao foro, atribuição de cada membro jurídico; a "ilusão" da instantânea interrupção da violência frente a realidade do litígio; dilação entre a denúncia e julgamento, com exigência de rever o ofensor e vivenciar novamente ocorridos danosos, provocando falta de interesse na condenação; insensibilidade de servidores do Judiciário diante da vítima e principalmente de profissionais forenses juntamente com a ausência de empatia quanto aos agentes jurídicos, exteriorizando desconfiança no que pese o depoimento da vítima, receio de novos conflitos, tal como, instigação do ofensor, fazendo a vítima, muitas vezes, ceder e abster-se de continuar com o processo investigatório.

Costa (2014, p. 79) tece "apesar da inovação da Lei Maria da Penha, os agressores não se sentem intimidados e muito menos punidos pelas violações cometidas, uma vez que tornam a cometer novas agressões, chegando ao homicídio". 
O modelo tradicional (retributivo) de justiça criminal fracassou há muito em sua promessa de combate à criminalidade, em todas as suas formas. A criminologia crítica, movimento surgido nos anos sessenta, contestou de forma veemente o caráter seletivo do sistema penal e as instituições repressivas: as prisões não diminuem as taxas de criminalidade, ao contrário, em razão das péssimas condições dessas instituições e do contato deletério entre presos perigosos e outros que praticaram infrações de médio potencial ofensivo, transformam-se em "fábricas de delinquentes", e estes, quando soltos, voltam a delinquir, razão pela qual os índices de reincidência são alarmantes. O sistema penal também é altamente seletivo, tanto em sua criminalização primária, quanto secundária, incidindo quase que exclusivamente nos indivíduos que compõem as camadas mais vulneráveis da sociedade, basta analisar qualquer pesquisa acerca da população carcerária que veremos que a sua maioria é composta por pobres, negros e analfabetos. (MESQUITA, 2015, p. 93)

Desse modo, como meio de suprir o mal praticado, não existe conflito nem providência para a prevenção de novas violências de gênero. Assim, é imperioso indicar novas formas de resolução de conflito que incitem a verdadeira reparação do dano, seja ele para a vítima, seja para o ofensor ou comunidade. (COSTA 2014).

Além disso, visando dirimir o ciclo da violência, um dos métodos adotados pelo Judiciário pode ser a autocomposição, seja como mediação ou conciliação, tendo em vista que o diálogo entre os envolvidos motiva a compreensão do conflito e visa cessá-lo. Também, a autocomposição é uma espécie de justiça restaurativa, considerando que com diálogo e a condução deste pelo magistrado, os envolvidos buscando realinhar o conflito acabam se adaptando e diminuindo o ciclo da violência. (OLIVEIRA, 2013 apud VASCONCELOS; SOUZA, 2019)

A Justiça Restaurativa, na concepção de Porto (2016, p. 136) "[...] é a força da comunidade, ou seja, sua essência parte das relações humanas, do senso de pertencimento que dá sentido à construção e convivência comunitária."

Os trabalhos pioneiros a respeito do tema iniciaram na segunda metade da década de 1970, em virtude do descontentamento marcante diante do sistema tradicional, exteriorizado através de quadro inoperante, respaldando a adesão de um outro modelo que visasse a condução dos conflitos, qual, seja, as práticas restaurativas. Já no Brasil, os primeiros contatos com as práticas foram realizados em 2005, através do projeto "Promovendo Práticas Restaurativas no Sistema de Justiça Brasileiro", onde houve três projetos norteadores: em Porto Alegre/RS, São Caetano do Sul/RS e em Brasília/ DF. (DIEHL; PORTO, 2016)

Cumpre ressaltar que os primeiros projetos foram desenvolvidos no âmbito da Justiça da Infância e Juventude, através dos círculos de construção de paz ou restaurativos. Já em Brasília/DF, a mediação vítima-ofensor foi adotada em contextos de menor potencial ofensivo, englobando ofensores adultos. Em São Paulo, houve aplicação preventiva, evitando a judicialização do conflito. Já no Rio Grande do Sul, a aplicação ocorreu na fase de execução de medida socioeducativa, bem como, em casos de conflitos escolares. Ademais, houve expansão do conhecimento em virtude de carências locais, adotando círculos de construção de paz, os quais se ampliaram, conquistando, desta forma, autonomia relativa para o projeto, em razão de vincular-se a organizações privadas, como a Associação dos Juízes do Rio Grande do Sul (AJURIS). (PORTO, 2016)

Diante de várias objeções vindas de operadores do Direito, a Justiça Restaurativa alcançou novo fomento com a Emenda n. 1 à Resolução 125 do Conselho Nacional de Justiça (CNJ) de 2013, onde trouxe a implementação em Tribunais de Justiças de "Núcleos Permanentes de Métodos Consensuais 
de Solução de Conflitos", bem como, a instigação para a instalação de programas de mediação penal ou outra prática restaurativa, intentando o emprego em conflitos de competência dos Juizados Especiais Criminais e dos Juizados da Infância e da Juventude e também as Varas de Família, Criminal, com uma notoriedade para a Vara de Violência Doméstica e Familiar, tendo em vista uma cooperação do Tribunal de Justiça com a Associação dos Magistrados Brasileiros, Supremo Tribunal Federal e sociedade civil. (PORTO, 2016)

Desse modo, através da Justiça Restaurativa a mulher que foi vítima de violência doméstica poderá solucionar seu litígio com independência com a cooperação do ofensor e da comunidade, na busca por uma solução apropriada, rompendo o desequilíbrio de poder entre mulheres e homens na sociedade. (PELAES, 2019)

Não é somente a resolução do conflito e a reparação que carecem de ser alcançados pela justiça restaurativa, mas também a relação entre o ofensor e a vítima. Tencionando alcançar estas finalidades, é primordial que o processo deliberativo não seja um feito restrito de autoridade, mas sim, partilhado com os indivíduos que estão abrangidos no conflito, seja eles: ofensor, vítima e comunidade. Destarte, uma deliberação conjunta, além de possuir mais aceitabilidade, conseguiria propiciar a melhora em danos provenientes do delito causado contra a vítima, bem como, no procedimento de transformação do ofensor. (PINTO, 2005)

Especificamente, em ocorrências de violência domésticas, onde mulher silencia, seja por vergonha, sensação de impotência ou medo, a abordagem restaurativa oportuniza o rompimento do silêncio, onde a vítima expõe as consequências das agressões ao ofensor e este identifica o que causou. (COSTA, 2014, p. 85)

Como ponto de partida para compreender o que vem a ser Justiça Restaurativa, é fundamental dominar os princípios que a conduzam, mesmo que em alguns casos, manifestem diferenciação de culturas, todavia, os princípios sem mantem os mesmos. Desta forma, é primordial entendê-la, a fim de analisar o delito com outros olhos. (ZEHR, 2008 apud COSTA, 2014)

Sobre os princípios basilares da Justiça Restaurativa Saliba (2009 apud OLIVEIRA, 2015, p. 9394) cita como inerentes à Justiça Restaurativa:

(i) princípio do processo comunicacional em que, segundo ele, deve vigorar a ética da solidariedade, uma vez que um dos objetivos principais dessa espécie de justiça é viabilizar o encontro e o diálogo entre as partes; (ii) princípio do consenso, que tem como pressuposto o respeito às diferenças culturais existentes entre as partes, cuja participação no processo restaurativo deve ser voluntária; (iii) princípio da resolução alternativa e efetiva do conflito, uma vez que, por se tratar de maneira alternativa para solucionar os conflitos a que as partes aderem voluntária e conjuntamente, por meio do diálogo, elas apontarão a solução, comprometendo-se a cumprir o acordo firmado, o que assegura maior efetividade na adoção das medidas apontadas; e (iv) princípio do respeito absoluto aos direitos humanos e à dignidade da pessoa humana.

Do mesmo modo, a Justiça Restaurativa não diz respeito a união do casal novamente, mas gerar um caminho que os envolvidos possam ter um contato harmônico, independentemente se juntos ou separados. Tal comunicação se faz de essencial relevância, pois, a violência doméstica não compreende somente a vítima e o ofensor, mas, da mesma forma, filhos e familiares, visto que não devem ser distanciados de um ou de outro, exceto em casos que o mesmo venha a correr ameaça. (STELLET; MEIRELLES, 2016) 
No Brasil, diante da ausência de legislação específica regulamentadora, existe a Resolução 225/2016 do CNJ que positivou a implementação do procedimento restaurativo na Judiciário. A nível internacional, há respaldo na Resolução 2002/12 da ONU. Ainda, dispõe o artigo sexto da respectiva Resolução que a prática pode ser utilizada em todos os estágios do processo, conforme a legislação vigente. (DEPEN, 2017). Outrossim, a competência caberá ao CNJ, com a cooperação da sociedade, dentre demais atribuições, desenvolver um projeto com o propósito de promover a Justiça Restaurativa no Brasil. (SILVEIRA, 2019)

Cumpre ressaltar que em tais práticas, não é somente vítima e ofensor que se enquadram como envolvidos, mas todos aqueles afetados pelo crime. Também é estabelecido como facilitador a pessoa que é responsável por ir em busca do "acordo", entre o ofensor e vítima, conforme Resolução no 225/2016 do CNJ.

Bem assim, a realização das técnicas, conforme elencado na Resolução da ONU 2002/12, somente dar-se-á em casos que há indícios suficientes de autoria e consentimento dos envolvidos, sendo que as imposições devem ser proporcionais ao delito cometido, não podendo ferir princípios constitucionais, como a dignidade da pessoa humana. (SILVEIRA, 2019)

Resumidamente, a mediação compõe-se de um encontro presencial, onde o mediador apresenta, de maneira sucinta a situação que gerou o conflito, e após, os envolvidos são estimulados para que apresentem suas histórias, bem como, a vítima é motivada a narrar as sequelas perante o ocorrido. Feito isso, são trazidas as lacunas passíveis de reparação e identificação de atos para tais. Esse encontro desencadeia o empoderamento por meio do diálogo, acarretando a construção de uma decisão que às próprias se comprometem e se encarregam de cumprir. (MEIRELLES; YAZBEK, 2014 apud PORTO, 2016)

Já o modelo de conciliação terá início com uma reunião através dos envolvidos, sendo que se difere da mediação ao passo que o conciliador/facilitador é capaz de levantar prováveis soluções para a situação, sendo proibido eventual coação ou imposição dos envolvidos. (MEZZALIRA, 2018)

Dessa forma, o resultado restaurativo ocorre a partir de um procedimento restaurativo exitoso, considerando assim, a casual "pena" que será determinada ao ofensor, visando a composição entre os envolvidos, e, deste modo, reestabelecê-las as sociedade, conforme a Resolução da ONU 2002/12. (ONU, 2002/12)

Portanto, a justiça restaurativa é uma prática que auxilia e busca proporcionar o diálogo entre as vítimas e os ofensores e visando soluções para a pacificação do conflito, primando sempre pela sensibilidade e escuta dos envolvidos.

\section{CONSIDERAÇÕES FINAIS}

Embora existam previsões legais com o intuito de coibir a violência, a escassez de infraestrutura e políticas públicas para amparo de vítimas juntamente com a incerteza da reincidência as tornam ineficientes.

A cultura patriarcal fortemente enraizada gerou a submissão de mulheres, e dessa forma desencadeou a violência doméstica, bem como ocasionou o estopim para advento da Lei Maria da Penha no ordenamento jurídico. 
Através dos dados apresentados Atlas da Violência e DataSenado, a violência e os homicídios perpetuam e os números só aumentam, porém, o medo de realizar a denúncia ainda é um forte indicador de que existam subnotificações.

A chegada do Covid-19 no Brasil propiciou uma curva ascendente nos casos de violência, remodelando políticas públicas e concebendo novas, entretanto, com parcial êxito, visto que a rede estatal não fornece o suporte necessário, assim como o medo da contaminação e a dificuldade das vítimas se ausentarem dos lares.

Percebeu-se ainda que o sistema retributivo não é a melhor solução, considerando a sobrecarga do Poder Judiciário e a manutenção dos índices de violência, demonstrando que o sistema não possui a eficiência que muitos gostariam.

Desse modo, a Justiça Restaurativa obteve amplitude no Brasil ao passo que foi se difundindo e alcançando o âmbito das Varas de Violência Doméstica e Familiar por meio da Emenda à Resolução 125 do CNJ, possibilitando a utilização em casos de Violência Doméstica através de modelos e com base nos princípios elencados na Resolução 225/2016 e 2002/16.

Portanto, podemos concluir que há possibilidade da aplicação da Justiça Restaurativa como política pública em casos de violência doméstica visando o acesso à justiça e a pacificação de conflito, atendendo a Resolução 125 e 225 do CNJ, bem como que o rol de práticas não é taxativo, desde que o meio para a solução do conflito parta do diálogo e que respeite os princípios que a regem.

\section{REFERÊNCIAS}

ANDRADE, Conceição. Um vírus e duas guerras: Mulheres enfrentam em casa a violência doméstica e a pandemia da Covid-19. Ponte Jornalismo [online]. Disponível em: <https://ponte. org/mulheres-enfrentam-em-casa-a-violencia-domestica-e-a-pandemia-da-covid-19/> Acesso em: 20 jul. 2020.

BIANCHINI, Edgar Hrycylo. Edgar Hrycylo. Justiça Restaurativa: um desafio a práxis jurídica. Campinas: Servanda, 2012.

BIANQUINI, Heloisa. Combate à violência doméstica em tempos de pandemia: o papel do Direito. Revista eletrônica Consultor Jurídico, São Paulo, 2020. Disponível em:< https://www.conjur.com. br/2020-abr-24/direito-pos-graduacao-combate-violencia-domestica-tempos-pandemia>. Acesso em: 20 abr. 2020.

BITTENCOURT, Cezar Roberto. Tratado de Direito Penal: parte geral. 18. ed. São Paulo: Saraiva, 2012

BRASIL. Congresso Nacional. Senado Federal. Observatório da Mulher Contra a Violência.

Violência doméstica e familiar contra a mulher Pesquisa DataSenado, Brasília, Jun. 2017. Disponível em: <https://www12.senado.leg.br/institucional/datasenado/arquivos/aumenta-numero-demulheres-que-declaram-ter-sofrido-violencia>. Acesso em: 20 abr. 2020.

BRITO, A. M. B. Concurso de Crimes e Violência Doméstica. In: MIGUEL, João Manuel da Silva. Violência Doméstica: Jurisdição Penal e Processual Penal. 01. ed. Lisboa: Centro de Estudos Judiciários, 2018. Disponível em: <http://www.cej.mj.pt/cej/recursos/ebooks/penal/eb_ ViolenciasDomesticas.pdf. > Acesso em: 05 de out. 2019. p. 09-14.

CAVALCANTI, LUdmila Fontenele. Prevenção da violência sexual: avaliando a atenção primária no Programa de Assistência Integral à Saúde da Mulher. In: PASTORINI, Alejandra; ALVES, Andrea 
Moraes; GALIZIA, Silvina V (org). Estado e cidadania: reflexões sobre as políticas públicas no Brasil contemporâneo. 01. ed. Rio de Janeiro: Editora FGV, 2018. p. 201-203.

COSTA, Carla Souza da. A Justiça Restaurativa como Política Pública de Prevenção nos casos de Violência de Gênero: uma proposta a partir dos Círculos Restaurativos. 2014. Dissertação (Mestrado em Direito) - Universidade de Santa Cruz do Sul, Santa Cruz do Sul, 2014.

DEPEN. Ministério da Justiça e Cidadania. Manual de Gestão para alternativas penais: práticas de justiça restaurativa. Departamento Penitenciário Nacional, Brasília, 2017. Disponível em: http: <// depen.gov.br/DEPEN/dirpp/cgap/modelo-de gestao/prticasdejustiarestaurativas.pdf.> Acesso em: abr. 2020.

DIAS, Maria Berenice. A Lei Maria da Penha na Justiça. 6. ed. Salvador: Editora JusPodivm, 2019.

. Manual de Direito das Famílias. 4. ed., rev., atual. e ampl. São Paulo: Revista dos Tribunais, 2007.

DIEHL. R. C; PORTO, R. T. C. A cultura simbólica e punitiva do direito penal no Brasil: os avanços culturais e sociais e os desafios da política nacional de justiça restaurativa a partir da resolução $n^{\circ}$ 225 CNJ/2016. In: Justiça Restaurativa e Cidadania, Publicatio UEPG, 24v. n. 03, Ponta Grossa, 2016. Disponível em: < <http://www.revistas2.vepg.br/index.php/sociais> Acesso em: 02 jun. 2020.

ESSY, Daniela Benevides. A Lei Maria da Penha e a (in) eficácia do escopo preventivo no combate à violência contra a mulher. 2016. Trabalho de Conclusão de Curso de Direito. Universidade Federal do Rio Grande, Rio Grande, 2016. Disponível em: <http://repositorio.furg.br/bitstream/ handle/1/7620/Daniela\%20Benevides\%20Essy_4309492_assignsubmission_file_TCC\%20-\%20 Daniela\%20Benevides\%20Essy.pdf? sequence=1>. Acesso em: 14 abr. 2020.

GIDDENS. Anthony. Para Além da Esquerda e da Direita. 1. ed. São Paulo: Editora Unesp, 1996.

GONZATTI, R. M.; SILVA, A. C. D. A violência contra as mulheres do campo como fenômeno de violação dos direitos humanos: desafios às políticas públicas no enfrentamento de um problema social invisível e isolado pelas grandes distâncias. In: COSTA, M. M. M. da; GIEHL, R. C. (Org). Direito, Cidadania \& Políticas Públicas XII. Curitiba: Editora Ithala Ltda, 2019. p. 180-207.

IPEA. Instituto de Pesquisa Econômica Aplicada e Fórum Brasileiro de Segurança Pública. Atlas da violência 2019. Brasília: Rio de Janeiro: São Paulo: 2019. Disponível em: < http://www.ipea.gov.br/ portal/images/stories/PDFs/relatorio_institucional/190605_atlas_da_violencia_2019.pdf. Acesso em: 25 de mar. 2020.

KIST, Fabiana. O Valor da Vontade da Vítima de Violência Conjugal para a Punição do Agressor: Oficialidade, oportunidade e justiça restaurativa. 1. ed. Leme: São Paulo, 2019.

LE MONDE, Féminicides: Mécanique d'un crime annoncé. Le Monde, França, 02 jun. 2020. Disponível em: <https://www.lemonde.fr/societe/article/2020/06/02> Acesso em: 02 jun. 2020.

LOPES JUNIOR, Aury Celso Lima. Fundamentos do Processo Penal: introdução crítica. 06. ed. São Paulo. Editora Saraiva, 2016.

LOPES, Bárbara Martins. Da violência sexual intra-matrimônio: Entendendo o débito conjugal no mundo hodierno. Âmbito Jurídico, São Paulo, 31 maio. 2005. Disponível em:<http://jusvi.com/ doutrinas_e_pecas/ver/1897> Acesso em 15 de jul 2020.

MARCANTONIO, Roberta Brasiliense. A implementação da mediação como política Pública de Pacificação dos Conflitos Familiares por meio da Resolução N 125 de Conselho Nacional de Justiça. Dissertação (Mestrado em Direito) - Universidade de Santa Cruz do Sul, Santa Cruz do Sul, 2014. 
MAZZI, Carolina. Violência doméstica dispara na quarentena: como reconhecer, proteger e denunciar. O Globo Sociedade, Rio de Janeiro, 01 de maio de 2020. Disponível em: <https:// oglobo.globo.com/sociedade/coronavirus-servico/violencia-domestica-dispara-na-quarentenacomo-reconhecer-proteger-denunciar-24405355>. Acesso em: 04 maio de 2020.

MEIRELLES, Delton R. S.; STELLET, Gabriela Sepúlveda. Justiça Restaurativa: Um caminho possível nos casos de violência doméstica. Trabalho de Conclusão de Curso de Direito. Universidade de Universidade Federal Fluminense, Niterói, Rio de Janeiro, 2016.

MENDES, Letícia. Risco de aumento de casos durante confinamento pelo coronavírus preocupa rede de combate à violência doméstica. Gaúcha Zero Hora. Porto Alegre, 06 de abril de 2020. Disponível em: <https://gauchazh.clicrbs.com.br/seguranca/noticia/2020/04/risco-de-aumentode-casos-durante-confinamento-pelo-coronavirus-preocupa-rede-de-combate-a-violenciadomestica-ck8ovs0yo00cq01ntdz447mh8.html>. Acesso em: 01 de maio de 2020.

MESQUITA, Marcelo Rocha. Justiça Restaurativa: uma opção na solução de conflitos envolvendo violência doméstica e familiar contra a mulher. Dissertação (Mestrado em Direito) - Universidade Federal de Sergipe, São Cristóvão, Sergipe, 2015. Disponível em: <https://ri.ufs.br/bitstream/ riufs/4360/1/MARCELO_ROCHA_MESQUITA.pdf> Acesso em: 02 abr. 2020.

MEZZALIRA, Ana Carolina. A Justiça Restaurativa e sua normatização no Brasil: a resolução 225 do CNJ. Jus Navegandi, Piauí, ano 23, maio de 2018. Disponível em: <https://jus.com.br/artigos/65804> Acesso em: 6 maio 2020.

MORAES, L. Q; RUBENS, N. Advocacia Pro Bono em Defesa da Mulher Vítima de Violência. Campinas: Editora da Unicamp; São Paulo: Imprensa Oficial do Estado, 2002.

OLGA, Think. Eixo 1: Violência contra a mulher. Think Olga, Think Eva [online], 2020. Disponível em: <https://www.thinkolga.com/violencia-contra-mulheres>. Acesso em: 15 abr. 2020.

OLIVEIRA, Luciano. Técnicas de resolução de conflitos: autocomposição e heterocomposição. São Paulo: Conteúdo Jurídico, 2013.

ONU. Assembleia Geral das Nações Unidas. Resolução 2002/12. Princípios básicos para utilização de programas de justiça restaurativa em matéria criminal. 2012. Disponível em: <http://www.onubrasil.org.br/doc_crianca.php> Acesso em: 25 abr. 2020.

PELAES, Rosileia dos Santos de Oliveira. A justiça restaurativa como política pública para o enfrentamento a violência doméstica e familiar contra a mulher: um estudo das ações do poder judiciário na vara de violência doméstica da Comarca do município de Santana/ap. 2019. 140 f. Dissertação (Mestrado Acadêmico ou Profissional em XX) - Universidade Estadual do Ceará, 2019. Disponível em: <http://siduece.vece.br/siduece/trabalhoAcademicoPublico.jsf?id=90670> Acesso em: 6 de abril de 2020

PINTO, Renato Sócrates Gomes. Justiça restaurativa é possível no Brasile In: SLAKMON, Catherine; DE VITTO, Renato C. P.; PINTO, Renato S. G. et al (orgs.). Justiça restaurativa. Brasília: Ministério da Justiça e Programa das Nações Unidas para o Desenvolvimento- PNUD, 2005. Disponível em: < https://www.pucsp.br/ecopolitica/downloads/biblioteca_direito/JustCA_restaurativa_PNUD_2005. pdf > Acesso em: 10 abril de 2020, p. 19-40.

PORTO, Pedro Rui da Fontoura. Violência Doméstica e Familiar Contra a Mulher: Lei 11.340/06: análise crítica e sistêmica. 03. ed. Porto Alegre: Livraria do Advogado, 2014.

PORTO, Rosane Teresinha Carvalho. A implementação das práticas das políticas restaurativas na prevenção ao feminicídio enquanto política pública para os homens autores de violência de 
gênero no Brasil. Tese (Doutorado em Direito) - Universidade de Santa Cruz do Sul, Santa Cruz do Sul, 2016. Disponível em: < https://repositorio.unisc.br/jspui/bitstream/1 1624/1051/1/Rosane\%20 Teresinha\%20Carvalho\%20Porto.pdf> Acesso em: 02 jun. 2020.

SALIBA, Marcelo Gonçalves. Justiça restaurativa e paradigma punitivo. Curitiba: Juruá, 2009.

SARKIS, Stephanie Moulton. O Fenômeno Gaslighting: Saiba como funciona a estratégia de pessoas manipuladoras para distorcer a verdade e manter você sob controle. 01. ed. São Paulo: Editora Cultrix, 2019.

SILVEIRA, Daniel Nazuti da. Justiça restaurativa: um sistema moderno de resolução de conflitos. Jus Navegandi, [online], 2019. Disponível em: < https://jus.com.br/artigos/71699/justica-restaurativaum-sistema-moderno-de-resolucao-de-conflitos > Acesso em: 04 maio de 2020.

TAMAYO, Giulia León. Questão de vida: Balanço Regional e Desafios Sobre o Direito das Mulheres a uma Vida Livre de Violência. 01. ed. Peru: CLADEN, 2000.

TORTEGA, Flávia. A força da Justiça Restaurativa em prol da humanidade. Jus Brasil [online] 2016. Disponível em: <https://draflaviaortega.jusbrasil.com.br/noticias/333165994/a-forca-da-justicarestaurativa-em-prol-da-humanidade>Acesso em: 3 de abr. 2020.

VALADARES, Leideane. Novos Mecanismos e Dispositivos Tecnológicos no Combate à Violência Doméstica e Familiar contra a Mulher no Estado do Maranhão. 01. Ed. Paraná: Viseu, 2017.

VASCONCELOS, Vanessa Lopes; SOUSA, J. R. E. Aplicação da justiça restaurativa ou retributiva nos casos de violência doméstica: um estudo dos impactos nos sujeitos da relação. Âmbito Jurídico, São Paulo, jun. 2017. Disponível em: <https://ambitojuridico.com.br/cadernos/direitos-humanos/ aplicacao-da-justica-restaurativa-ou-retributiva-nos-casos-de-violencia-domestica-um-estudo-dosimpactos-nos-sujeitos-da-relacao/>. Acesso em: 31 mar. 2020.

WALKER, L. E. The Battered Woman Syndrome. New York: Springer Publishing Company, 2009.

ZEHR, Howard. Trocando de lentes: um novo foco sobre o crime e a justiça. Tradução de Tônia Van Acker. São Paulo: Pala Athena, 2008. 